\title{
EFEITO DA COBERTURA VEGETAL DO SOLO SOBRE A ABUNDÂNCIA E DIVERSIDADE DE INIMIGOS NATURAIS DE PRAGAS EM VINHEDOS ${ }^{1}$
}

\author{
MARCOS ANTÔNIO MATIELLO FADINI², MURILLO DE ALBUQUERQUE REGINA ${ }^{3}$, \\ JOSÉ CARLOS FRÁGUAS ${ }^{4}$, JULIO NEIL CASSA LOUZADA ${ }^{5}$
}

\begin{abstract}
RESUMO - O controle de pragas da videira no Brasil restringe-se basicamente ao uso de inseticidas, devido à inexistência de trabalhos que visem a complementar o manejo de pragas através de controle biológico. Neste trabalho, objetivou-se verificar o efeito de diferentes coberturas vegetais nas entrelinhas de plantio de videira sobre a abundância e diversidade de potenciais inimigos naturais de pragas da videira no município de Caldas, região Sul do Estado de Minas Gerais. Foram testadas sete diferentes coberturas de solo (aveia-preta, aveia-preta e ervilhaca, ervilhaca, cobertura morta, uso de herbicida, capina mecânica e mato roçado). A cobertura vegetal do solo influenciou tanto a diversidade quanto a abundância de inimigos naturais, sendo o consórcio de aveia-preta e ervilhaca, cultivadas simultaneamente, o tratamento que proporcionou maior diversidade e abundância de inimigos naturais. Assim, a cobertura vegetal do solo pode, potencialmente, ser um componente importante em programas de manejo integrado de pragas na cultura da videira.
\end{abstract}

Termos para indexação: agroecossistema, policultivo, controle biológico, Vitis spp.

\section{EFFECTS OF COVER CROPS ON THE ABUNDANCE AND DIVERSITY OF NATURAL ENEMIES OF GRAPEVINE PEST}

\begin{abstract}
The control of grapevine pests in Brazil is only based in the use of chemical products. It is due to the whole absence of experimental works developed to test and evaluate alternative control systems, like the biological control. The objective of this work was to evaluate the effect of different types of cover crops, placed between the cultivation lines of grapevine, in the abundance and diversity of natural control arthropods of grapevine pests. The experiment was conduced in the EPAMIG, Caldas Research Farm, located in the Minas Gerais State, Brazil. They Were tested seven different systems of soil covering. The presence of vegetal covering was beneficial to improve the diversity as well as the abundance of biological control agents present on the grapevine crop. The cultivation of black oat and pea together, was the treatment that showed the better result to diversity and abundance. Therefore, the cover crops would be an important step to programs of pest control on grape looking for low environmental impact
\end{abstract}

Index terms: agroecossystem, policulture, biological control, Vitis spp.

\section{INTRODUÇÃO}

A diversidade de espécies de insetos correlaciona-se positivamente com diversidade de espécies vegetais em um local (van Emden e Williams, 1974), isto possivelmente devido à maior diversidade de habitats (complexidade estrutural) e à maior disponibilidade de recursos alimentares distribuídos no espaço e no tempo (Altieri, 1984). Assim, comunidades vegetais que possuem maior número de espécies, tendem a suportar também um maior número de espécies de insetos (Lawton e Strong, 1981).

Este referencial teórico é aplicável ao manejo de pragas (Liss et al., 1986), uma vez que o aumento da diversidade de espécies vegetais pode resultar na diminuição de algumas pragas, devido ao aumento da diversidade e abundância de artrópodes considerados inimigos naturais de pragas agrícolas (Altieri, 1991). Como exemplo, populações de pragas da cultura da videira têm apresentado níveis reduzidos quando em plantios onde outras espécies vegetais são manejadas simultaneamente (Altieri, 1987). A adoção deste tipo de prática agrícola apresenta algumas vantagens em relação aos métodos convencionais de controle de pragas, baseados apenas no uso de produtos químicos: i) baixo custo de implantação; ii) aumento do rendimento econômico das áreas com produção das culturas secundárias implantadas; iii) redução dos riscos de contaminação do ambiente e do trabalhador rural com inseticidas; iv) melhoria na qualidade dos frutos, por reduzir o nível de resíduos de inseticidas; v) método alternativo ao pequeno número de inseticidas registrados para o controle de pragas da videira (Andrei, 1999).

Contudo, ainda são poucos os trabalhos que visam a incrementar o manejo de pragas da videira através do controle biológico no Brasil (Reis e Melo, 1984; Reis et al., 1998), devido talvez à inexistência de constatações locais de potenciais inimigos naturais das pragas desta cultura. Alguns grupos de inimigos naturais, entretanto, podem apresentar potencialidade de controle de algumas pragas da cultura da videira (Hickel, 1998).

No caso específico da região Sul do Estado de Minas Gerais, o levantamento desta informação seria de grande importância socioeconômica, uma vez que o produtor desta região

1 (Trabalho 233/2000). Recebido: 23/10/2000. Aceito para publicação: 23/08/2001.

2 Pesquisador, M. Sc., EPAMIG-CTSM, CEP 37780-000 Caldas, MG. fadini@epamigcaldas.gov.br

3 Pesquisador, PhD, EPAMIG-CTSM, CEP 37780-000 Caldas, MG

4 Pesquisador, D. S., EMBRAPA/EPAMIG-CTSM, Campus da UFLA, CEP 37200-000 - Lavras, MG

5 Professor, D. S., Prof., Universidade Federal de Lavras, CEP 37200-000, Lavras, MG 
dispõe de poucos recursos financeiros para compra de inseticidas para o controle de pragas na cultura. As pragas mais freqüentes e severas encontradas nesta região são as marombas (Heilipus naevulus) e as cochonilhas-do-lenho (Duplaspidiotus spp.).

Objetivou-se, neste trabalho, verificar o efeito de diferentes coberturas vegetais (diversidade e complexidade estrutural) nas entrelinhas de plantios de videira sobre diversidade e abundância de possíveis inimigos naturais de pragas da videira, além de identificar grupos de inimigos naturais das pragas desta cultura. A hipótese testada é que o uso de coberturas vegetais intercalares em vinhedo estimula o crescimento e a manutenção de populações de inimigos naturais nesta cultura.

\section{MATERIAL E MÉTODOS}

O experimento foi conduzido na Fazenda Experimental de Caldas - EPAMIG, região Sul do Estado de Minas Gerais, Brasil $\left(21^{\circ} 55^{\prime} \mathrm{S} 46^{\circ} 23^{\prime} \mathrm{W}\right.$; Alt. $\left.1.150 \mathrm{~m}\right)$. O trabalho foi realizado em parreiral com dez anos de idade da cv Ives, sinonímia 'Folha-deFigo' (MG), Bordô (RS), Terci (PR), principal cultivar utilizada na região de Caldas. O sistema de condução era o de espaldeira com poda em cordão esporonado bilateral. Os diferentes tipos de cobertura vegetal foram semeados nas entrelinhas do vinhedo, em parcelas de aproximadamente $60 \mathrm{~m}^{2}$ dispostas inteiramente ao acaso e adjacentes, com três repetições.

Os tratamentos avaliados foram: cobertura da parcela com aveia-preta (Avena spp.); cobertura da parcela com a mistura de aveia-preta e ervilhaca (Vicia spp.) (1:1); cobertura da parcela com a leguminosa ervilhaca; cobertura morta de capim-gordura (Mellinis minutiflora); parcelas mantidas limpas constantemente por meio de aplicações periódicas de herbicida (glifosate); parcelas mantidas limpas por meio de capinas mecânicas manuais; parcelas mantidas com solo relvado permanente. A instalação dos tratamentos ocorreu durante abril de 1999.

As coletas de insetos foram realizadas com intervalos de duas semanas entre os meses de julho a setembro de 1999 e consistiram na captura de insetos sobre as plantas de videira e sobre a cobertura vegetal das entrelinhas com redes entomológicas em toda a extensão da parcela.

Para efeito de tabulação de dados, foi considerado inimigo natural potencial, espécies das famílias Vespidae, Formicidae (exceto Attini), Coccinellidae, Araneae, Chrysopidae, Syrphidae, amplamente referenciados na literatura como agentes de controle biológico (Van Driesche e Bellows, 1996). A identificação das espécies foi realizada com base na morfologia dos indivíduos coletados, sendo a diversidade de inimigos naturais o número de morfoespécies encontrado. Também foi registrada a abundância de inimigos naturais, considerada a contagem direta dos indivíduos por morfoespécies encontradas.

As análises estatísticas constaram de análise de variância, teste de médias (Tukey, 5\%) e análise de resíduos para verificar se o modelo estatístico escolhido explicava totalmente a variação sistemática do experimento.

\section{RESULTADOS}

A cobertura vegetal do solo influenciou tanto a abundância ( $\mathrm{P}<0,001)$ (Figura 1A) quanto a diversidade $(\mathrm{P}<0,001)$ (Figura 1B) de inimigos naturais no vinhedo avaliado. Dentre os tratamentos utilizados, a ervilhaca em cultivo solteiro e a ervilhaca consorciada com aveia-preta foram as coberturas vegetais que proporcionaram maior diversidade e abundância de inimigos naturais. Os menores valores, tanto para diversidade quanto para abundância de inimigos naturais, foram encontrados nos tratamentos de capina com herbicida, capina mecânica e cobertura morta. Assim, a diversidade e abundância de inimigos naturais correlacionaram-se positivamente com a diversidade vegetal nas entrelinhas dos vinhedos.

As famílias Vespidae, Formicidae (exceto Attini) e Coccinellidae foram as que apresentaram o maior número de indivíduos coletados. Também Araneae, Chrysopidae e Syrphidae foram coletadas, contudo em menor número.

A família Vespidade, dentre as registradas neste trabalho, seria a de maior potencial no controle das pragas da cultura da videira, devido aos espécimens ocorrerem em maior número e também por serem exímios predadores de lagartas (Hickel, 1998).

\section{DISCUSSÃO}

A manutenção da diversidade vegetal, tanto dentro das áreas de cultivo da videira quanto em áreas adjacentes a esta, aparentemente estimula a manutenção de populações de inimigos naturais das pragas. Este padrão de diversidade é identificado, também, em outras culturas (Altieri e Letournaeu, 1984). Este fato deve-se provavelmente ao aumento e distribuição de alimento e à melhoria das condições para crescimento, reprodução e refúgio destas populações.

Neste trabalho, foi identificada uma relação positiva entre a diversidade e a abundância de inimigos naturais de pragas e a cobertura vegetal nas entrelinhas de vinhedos. Os maiores valores médios de diversidade e abundância de inimigos naturais foram encontrados nos tratamentos onde se encontravam duas espécies vegetais cultivadas simultaneamente: neste caso, ervilhaca e aveia-preta, enquanto os menores valores médios foram encontrados nos tratamentos onde a cobertura vegetal do solo foi totalmente retirada: neste caso, onde foi feita a capina mecânica total das parcelas ou onde foi aplicado herbicida, demonstrando que o manejo da cobertura vegetal do solo influencia as populações de inimigos naturais de pragas da videira.

As famílias Formicidae (exceto Attini) e Vespidae foram as que apresentaram maior número médio de indivíduos ao longo das coletas, devido, provavelmente, ao fato de serem insetos sociais. Estas famílias são importantes inimigos naturais, agindo como predadores (Auad et al., 1997) e, ao que parece, poderiam potencialmente ser utilizadas em programas de manejo integrado ou controle biológico de pragas da videira.

Algumas restrições, contudo, devem ser mencionadas para que a utilização de culturas intercalares como método de manutenção de inimigos naturais em vinhedos possa ser usada de forma eficiente: i) após a poda de inverno, devem-se realizar capinas nas linhas de plantio para que não haja competição por umidade e nutrientes no solo entre as videiras e as culturas 
A)

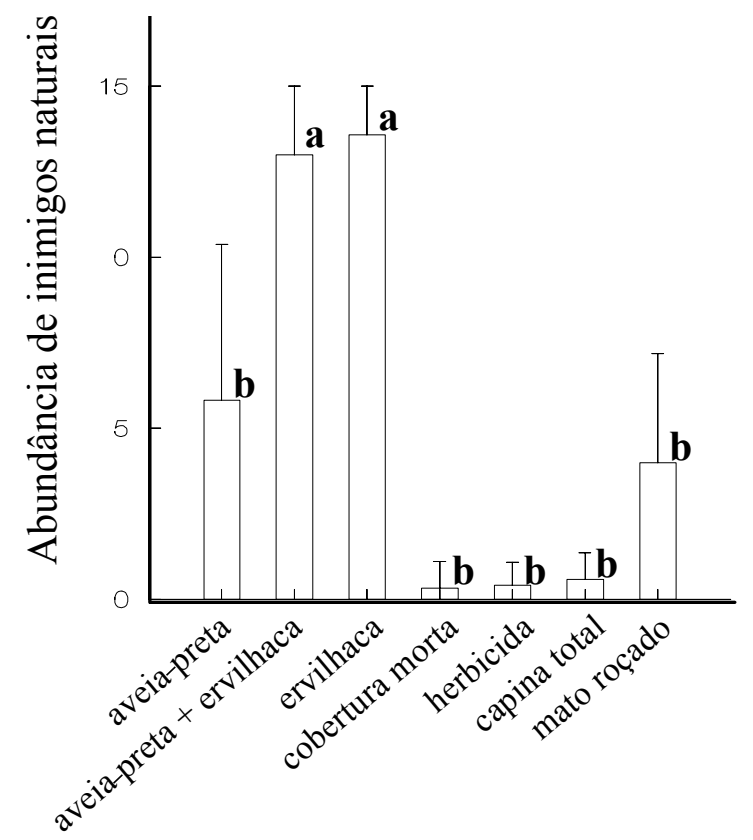

B)

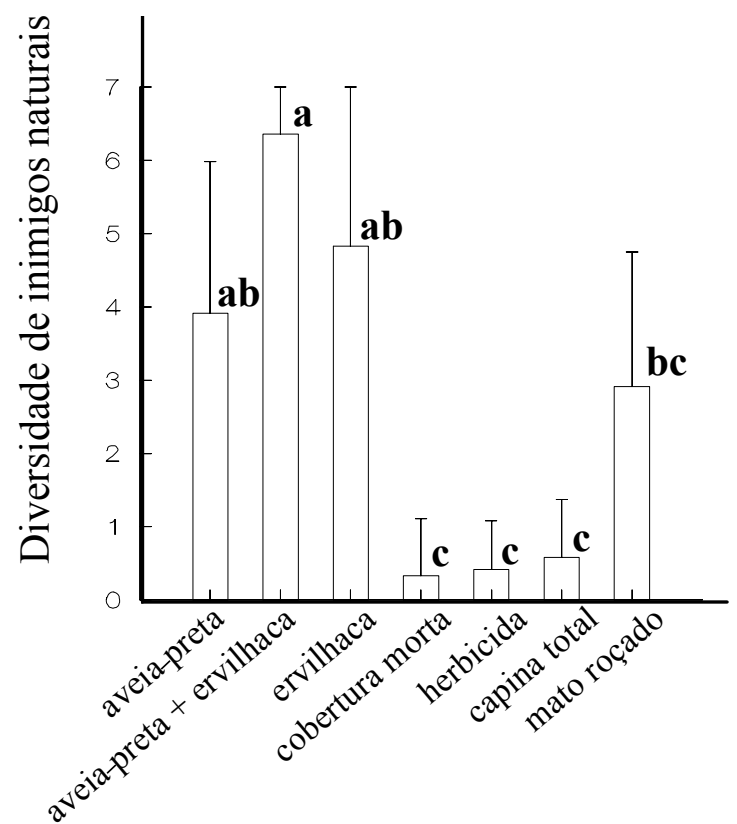

FIGURA 1 - Abundância (A) e diversidade (B) de inimigos naturais de pragas em função da cobertura vegetal das entrelinhas de vinhedo. Caldas-MG, 1999.

intercalares; ii) em locais onde a pérola-da-terra é uma praga freqüente, as culturas intercalares podem ser hospedeiras desta praga; iii) e vespas, em situações de escassez de recursos alimentares, também podem provocar injúrias a bagas maduras (Hickel e Schuck, 1995).

Assim, a manutenção da cobertura vegetal do solo pode vir a ser um componente em um programa de manejo integrado de pragas da videira, justificando a aplicação desta técnica. Contudo, é importante ressaltar que não foi registrada a influência dos inimigos naturais coletados neste trabalho sobre as populações de pragas da videira na região. Este seria o passo seguinte, para se comprovar a potencialidade dos agentes de controle biológico presentes na cobertura vegetal no controle de pragas da videira.

\section{CONCLUSÃO}

A cobertura vegetal do solo em vinhedos influencia a diversidade e abundância de inimigos naturais de pragas em vinhedos, podendo vir a ser um componente em programas de manejo integrado de pragas na cultura de videira.

\section{AGRADECIMENTOS}

Os autores agradecem ao Dr. Marcos Botton e ao Dr. Eduardo Hickel, pela revisão crítica dos manuscritos, e ao técnico Daniel José Rodrigues, pela montagem do experimento.

\section{REFERÊNCIAS BIBLIOGRÁFICAS}

ALTIERI, M.A. Agroecology: The scientific basis of alternative agriculture. Boulder: Westveiw, 1987.210p.

ALTIERI, M.A. How best can we use biodiversity in agroecosystem. Outlook on Agriculture, Wallingford, v.20, n.1, p.15-23, 1991.

ALTIERI, M.A. Patterns of insect diversity in monocultures and polycultures of brussels sprouts. Protection Ecology, Amsterdam, v.6, p.227-232, 1984.

ALTIERI, M.A.; LETOURNAEU, D.K. Vegetation diversity and insect pest outbreaks. Critical Reviews in Plant Sciences, v.2, p. 131-169, 1984.

ANDREI. Compêndio de defensivos agrícolas. São Paulo: 1999. $672 \mathrm{p}$.

AUAD, A.M.; BUENO,V.H.P.; KATO, C.M.; GAMARRA, D.C. Ocorrência e flutuação populacional de predadores e parasitóides de Brachycaudus (Applelia) schwartzi (Börner) (Homoptera: Aphididae), em pesssegueiro, em Jacuí-MG. Anais da Sociedade Entomológica do Brasil, Piracicaba, v.26, n.2, p.257-263, 1997.

HICKEL, E.R. Pragas da videira. In.: BRAGA SOBRINHO, R.; CARDOSO, J.E.; FREIRE, F.C.O. (Ed.). Pragas de fruteiras tropicais de importância agroindustrial. Brasília:Embrapa CNPAT, 1998.p.191-209.

HICKEL, E.R.; SCHUCK, E. Vespas e abelhas atacando a uva no Alto Vale do Rio do Peixe. Agropecuária Catarinense, v.8, n.1, p.38-40, 1995.

LAWTON, J.H.; STRONG, D.R. Community patterns and competition in folivorous insects. The American Naturalist, Chicago, v.113, n.3, p.317-338, 1981. 
LISS, W.J.; GUT, L.J.; WESTIGARD, P.H.; WARREN, C.E. Perspectives on arthropod community structure, organization, and development in agricultural crops. Annual Review of Entomology, Palo Alto, v. 31,p.455-478, 1986.

REIS, P.R.; MELO, L.A.S. Pragas da videira. Informe Agropecuário, Belo Horizonte v.10, n.117, p.68-72, 1984.

REIS, P.R.; SOUZA, J.; GONÇALVES, N.P. Pragas da videria tropical. Informe Agropecuário, Belo Horizonte v.19, n.194, p.92$95,1998$.

VAN DRIESCHE, R.G.; BELLOWS, T.S. Biological Control. New York: Chapman \& Hall: New: 1996. 539 p.

VAN EMDEN, H.F.; WILLIAMS, G.F. Insect stability and diversity in agro-ecossystems. Annual Review of Entomology, Palo Alto, v.21, p.455-475, 1974. 